\title{
EFEKTIVITAS PELATIHAN ACCEPTACE AND COMMITMENT PADA REGULASI EMOSI PENDAMPING PANTI ASUHAN K SURABAYA
}

\author{
${ }^{1}$ Dian Erlina Wibisono, ${ }^{2}$ Nur Lutfiyah, ${ }^{3}$ William Hadi Seputro \\ Magister Psikologi Profesi, Fakultas Psikologi, Universitas Surabaya \\ dian.erlina858@gmail.com
}

\begin{abstract}
This study aims to reduce difficulties in regulating emotions through acceptance and commitment training (ACT). This training was carried out for children's companions at the $K$ Orphanage in Surabaya. The material was delivered in 6 sessions using the roleplay method, written assignments, games, lectures, group discussions, and audio visuals. The research design was a non-randomized one group pre-test post-test design. Fifteen child companions were involved to become participants in this training. Data were collected before and after six training sessions using the Difficulties In Emotion Regulation Scale (DERS) and Comprehensive Assessment of Acceptance Commitment Therapy Processes (CompACT) questionnaires. Quantitative data analysis showed that there was no significant difference in emotion regulation ability before and after training ( $p>0.05)$. However, there were differences in knowledge before and after the training provided $(p=0.0001, p>0.05)$. Based on these results, it can be concluded that ACT training is less effective in reducing difficulties in regulating emotions.
\end{abstract}

\section{Keywords: Difficulty In Regulating Emotions, Acceptance And Commitment Training, Orphanage}

\begin{abstract}
Abstrak: Penelitian ini bertujuan untuk menurunkan kesulitan dalam meregulasi emosi melalui acceptance and commitment training(ACT). Pelatihan ini dilakukan pada pendamping anak yang ada di Panti Asuhan K di Surabaya. Materi disampaikan dalam 6 sesi dengan metode roleplay, tugas tertulis, permainan, lecturette, diskusi kelompok, dan audio visual. Desain penelitian adalah non-randomized one group pre-test post-test design.Lima belas orang pendamping anak dilibatkan untuk menjadi partisipan dalam pelatihan ini. Data dikumpulkan sebelum dan sesudah enam sesi pelatihan dengan menggunakan angketDifficulties In Emotion Regulation Scale (DERS) dan Comprehensive Assesment of Acceptance Commitment Therapy Processes(CompACT). Analisis data kuantitatif menunjukkan bahwa tidak ada perbedaan signifikan dalam kemampuan regulasi emosi sebelum dan sesudah pelatihan ( $\mathrm{p}>0.05)$. Walau demikian, terdapat perbedaan pengetahuan sebelum dan sesudah pelatihan yang diberikan $(\mathrm{p}=0.0001, \mathrm{p}>0.05)$. Berdasarkan hasil ini dapat disimpulkan bahwa pelatihan ACT kurang efektif untuk menurunkan kesulitan dalam meregulasi emosi.
\end{abstract}

Kata Kunci: Kesulitan Dalam Meregulasi Emosi, Acceptance And Commitment Training, Panti Asuhan

\section{PENDAHULUAN}

Emerging adulthood merupakan salah satu fase perkembangan yang akan dialami setiap individu. Fase ini ditandai dengan adanya beberapa karakteristik, salah satunya adalah merasa sudah seharusnya menjadi dewasa, namun masih belum bisa bertanggung jawab penuh terhadap dirinya sendiri (Arnett, 2007).

Perasaan ini membuat individu pada masa emerging adulthood menjadi berfokus dengan dirinya sendiri, dalam arti fokus pada pilihan hidupnya untuk bisa menjadi mandiri. Selain karakteristik tersebut, emerging adulthood juga dicirikan dengan adanya ketidakstabilan karena 
WIBISONO- Efektivitas Pelatihan Acceptace 287

akan terjadi berbagai perubahan yang bisa menyebabkan adanya ketidakamanan secara emosi (Arnett dalam Zimmermann \& Iwansky, 2014). Perubahan yang terjadi antara lain perubahan peran dan adanya tuntutan yang lebih tinggi dalam tugas perkembangan (Roisman, dkk dalam Zimmermann \& Iwansky, 2014). Menurut hasil penelitian dari Zimmermann dan Iwansky (2014), emerging adulthood memiliki beberapa karakterisktik yang hampir sama dengan masa remaja, antara lain adanya kemarahan yang susah untuk diregulasi dengan menahan kemarahannya, serta penolakan terhadap rasa sedih.

Salah satu perubahan peran dan tuntutan dalam tugas ini terjadi pula pada para pendamping salah satu panti asuhan $\mathrm{K}$ di Surabaya. Para pendamping yang ada di panti tersebut kebanyakan termasuk pada usia emerging adulthood. Pada masa saat para pendamping ini masih berfokus pada dirinya, memiliki kewajiban baru untuk mengurus anakanak yang ada di panti. Peran ini merupakan peran yang penting karena mereka menggantikan peran orang tua untuk melindungi anak dengan memberikan rasa aman dan nyaman, menghindarkan anak dari hal-hal yang berpotensi mengancam kesejahteraan anak, memenuhi kebutuhan anak baik secara fisik dan psikis, memberikan dukungan secara emosional dan sosial pada anak, serta memberikan arahan pada anak untuk dapat membentuk kepatuhan anak pada normanorma yang berlaku (Carr, 2001). Selain itu, orang tua juga berperan dalam sisi intelektual pada anak yang dapat diwujudkan dengan cara memberikan stimulasi yang menunjang perkembangan kognitif, bahasa, dan emosional sesuai dengan usia anak.

Idealnya, seluruh kebutuhan dipenuhi oleh para pendamping yang menggantikan peran orang tua agar tidak terjadi dampak negatif pada anak. Salah satu dampak negatif yang bisa terjadi pada anak adalah rendahnya tingkat kesejahteraan anak (Solari \& Mare, 2012), kurang terpenuhinya kebutuhan dasar anak (Yendork \& Somhlaba, 2014), berkurangnya minat bermain, produktivitas, hubungan sosial, dan tingkat kesehatan anak (Cluver, Gardner, \& Operario, 2008). Hal ini disebabkan oleh kondisi di dalam panti yang berpotensi membuat rasa aman dan privasi anak menjadi berkurang.

Untuk itulah dibutuhkan beberapa kemampuan yang seharusnya dimiliki oleh pengasuh (Surjastuti, 2012), yaitu memiliki bekal pengetahuan mengenai perkembangan anak yang akan membuat pendamping mampu memahami anak secara menyeluruh, mengenali kemungkinan kemunculan masalah pada anak (baik masalah perilaku, sosial, dan emosi), melakukan pengawasan pada anak, dan menyediakan kebutuhan fisik anak. Selain itu, pendamping juga diharapkan telah memiliki pengalaman interaksi dengan anak-anak, sehat secara jasmani dan rohani, serta memiliki bersedia untuk berkomitmen dalam menjalankan tugas mengasuh anak. Hal-hal tersebut penting dimiliki pendamping untuk dapat menjamin adanya kesejahteraan anak serta terpenuhinya kebutuhan anak, tidak hanya secara fisik dan sosial, namun juga emosional. 
Kemampuan lain yang juga penting merupakan salah satu panti yang menampung dimiliki oleh pendamping adalah kemampuan anak-anak yang tidak diterima dan/atau tidak untuk meregulasi diri dan menyesuaikan diri. memiliki orang tua yang mampu merawat Kedua kemampuan ini diprediksi dapat mereka. Panti asuhan ini memperkerjakan 21 mencegah individu mengalami permasalahan psikologis (Neven, Rathus, \& Greene, dalam Rif'ati \& Suryanto, 2018). Selain mencegah terjadinya permasalahan psikologis, pendamping yang dibagi menjadi divisi bayi, balita, anak usia sekolah, dan remaja. Panti asuhan dengan latar belakang Kristiani ini kemampuan regulasi emosi akan membantu mengoptimalkan perkembangan emosi anak. Garner dan Spears (2000) menjelaskan bahwa regulasi emosi merupakan kontrol terhadap pngalaman emosional, ekspresi emosi, dan kemampuan dalam mengurangi gairah emosi. Semakin baik kemampuan dalam regulasi emosi, maka individu tersebut akan menampilkan kompetensi yang baik secara sosial, relasi sosial yang baik, serta adanya perilaku menolong dengan sukarela (Dingle \& Fay, 2016).

Sebaliknya, kesulitan dalam meregulasi emosi diartikan sebagai kurangnya kapasitas diri dalam mendiferensiasi ragam emosi, rendahnya kemampuan merespons secara spontan emosi yang dimiliki, sdan kurangnya kemampuan pengelolaan emosi negatif (Gross \& Munoz, 1995). Adanya kesulitan dalam meregulasi emosi ini akan berkaitan dengan perilaku agresi fisik dan agresi secara sosial yang jika tidak diatasi maka akan berpotensi mengarah pada perilaku kekerasan (Dingel \& Fay, 2016; Khakbaz, Farhoudian, Azkhosh, Dolatshahi, et al,2016).

Kondisi pendamping yang ideal seperti yang diharapkan ini sayangnya tidak ditemukan di panti asuhan K Surabaya. Panti asuhan K memiliki harapan agar para pendampingnya mampu membina dan mendidik anak dengan nilai-nilai Kristiani. Para pendamping diharapkan juga dapat menerapkan nilai-nilai Kristiani yang dianut dalam pengasuhannya. Pada kenyataannya, terdapat beberapa perilaku pendamping yang dirasa kurang mencerminkan nilai-nilai Kristiani. Pendamping mengaku bahwa mereka terkadang membentak, memukul, atau memarahi anak. Biasanya perilaku ini muncul karena merasa bahwa anakanak kurang mau menuruti instruksi atau arahan dari pendamping.

Sebenarnya, pendamping mencoba mengatasi hal ini dengan cara menghindari situasi yang menimbulkan emosi negatif seperti menghindari interaksi dengan anak-anak yang menurutnya sulit. Misalnya menghindari anak yang suka menangis atau memunculkan perilaku temper tantrum. Tetapi, jika mereka terpaksa menghadapi situasi tersebut, maka pendampin cenderung menjadi kurang mampu mengendalikan perilakunya. Keseluruhan perilaku yang dimunculkan ini membawa beberapa dampak pada relasi antara pendamping dan anak. Hubungan antara pendamping dan anak menjadi kurang hamonis. Saat pendamping memarahi anak, anak memang cenderung menuruti instruksi 
WIBISONO- Efektivitas Pelatihan Acceptace 289

pendamping, namun pada situasi lainnya, anak tetap tidak menurut. Selain itu, anak juga yang ditanamkan didalam panti.

cenderung hanya menurut dan takut pada pendamping-pendamping yang sering memarahinya. Hal ini membuat para pendamping memiliki julukan tertentu sesuai dengan perilaku yang sering mereka munculkan. Julukan ini pun mendorong pendamping memunculkan perilaku sesuai dengan julukan tersebut.

Kejadian tersebut bisa muncul karena adanya tiga permasalahan yang ditemukan oleh peneliti yakni, (1) Pendamping belum memiliki pengetahuan dan kemampuan untuk tetap tenang dan mampu mengatur emosinya dalam menghadapi anak-anak, terutama anak-anak yang sulit diatur; (2) Pendamping belum mengetahui cara dan belum memiliki kemampuan untuk mendisiplinkan anak, memahami perasaan anak, sehingga kurang dapat menerapkan nilai-nilai kristiani dalam mengasuh anak; (3) Pendamping belum mampu mengontrol emosinya sehingga mengganggu konsentrasi dalam mengasuh anak. Berdasarkan ketiga permasalahan yang telah disebutkan, peneliti memutuskan menggunakan pelatihan ACT (acceptance and commitment training) untuk mengatasi permasalahan yang terjadi. Adanya pelatihan ACT diharapkan dapat meningkatkan penerimaan emosi negatif pendamping untuk mempermudah proses regulasi emosi negatif yang dirasakan, meningkatnya fleksibilitas psikologi pendamping agar dapat menerima berbagai perubahan karakteristik anak yang diasuh, dan terciptanya komitmen pengasuh untuk

\section{METODE}

Pelatihan yang dilakukan dalam penelitian ini menggunakan metode eksperimen nonrandomized one group pre-test post-test design.

\section{Partisipan}

Partisipan penelitian ini merupakan pendamping di panti asuhan $\mathrm{K}$ sebanyak 15 partisipan. Minimnya jumlah pendamping yang ada mengakibatkan peneliti menggunakan metode penelitian terkait karena tidak memungkinkan untuk membagi partisipan menjadi dua kelompok (Siyoto \& Sodik, 2015).

Penjabaran mengenai peserta pelatihan dapat dilihat pada tabel di bawah ini:

Tabel 1 Deskripsi Peserta Pelatihan

\begin{tabular}{cccl}
\hline No. & $\begin{array}{c}\text { Nama } \\
\text { Peserta }\end{array}$ & Usia & $\begin{array}{c}\text { Jenis } \\
\text { Kelamin }\end{array}$ \\
\hline 1 & $\mathrm{~A}$ & 47 & Laki-laki \\
2 & $\mathrm{~B}$ & 24 & Perempuan \\
3 & $\mathrm{C}$ & 22 & Perempuan \\
4 & $\mathrm{D}$ & 23 & Perempuan \\
5 & $\mathrm{E}$ & 39 & Perempuan \\
6 & $\mathrm{~F}$ & 23 & Laki-laki \\
7 & $\mathrm{G}$ & 22 & Perempuan \\
8 & $\mathrm{H}$ & 23 & Laki-laki \\
9 & $\mathrm{I}$ & 24 & Perempuan \\
10 & $\mathrm{~J}$ & 24 & Laki-laki \\
11 & $\mathrm{~K}$ & 24 & Laki-laki \\
12 & $\mathrm{~L}$ & 25 & Perempuan \\
13 & $\mathrm{M}$ & 22 & Laki-laki \\
14 & $\mathrm{~N}$ & 24 & Laki-laki \\
15 & $\mathrm{O}$ & 26 & Perempuan \\
\hline
\end{tabular}

Alat Ukur dan Prosedur

Pelatihan yang dilakukan mengadopsi enam tahapan dari acceptance and commitment therapy (ACT) untuk dijadikan sebuah pelatihan untuk menurunkan kesulitan subjek 
meregulasi emosi. Pelatihan ini dibagi menjadi enam sesi yang dibagi menjadi tiga hari dikarenakan keterbatasan waktu dari partisipan yang juga harus menjalankan kewajibannya. Keseluruhan proses pelatihan menggunakan metode psikoedukasi yang telah digabung dengan metode training seperti penggunaan roleplay, games, writing task, lecturette, small group discussion, dan audio visual(Lawson, 2015).

Efektivitas penelitian ini akan dilakukan dengan memberikan dua alat ukur, yaitu DERS (difficulties in emotion regulation scale) dan CompACT (comprehensive assesment of acceptance commitment therapy processes). Skala DERS akan digunakan untuk mengukur kesulitan meregulasi emosi pendamping. Pada skala ini akan diukur 6 dimensi kesulitan meregulasi emosi, yaitu nonacceptance of emotional responses, difficulties engaging in goal-directed behavior, impulse control difficulties, lack of emotional awareness, limited access to emotion regulation strategies, dan lack of emotional clarity. Sementara skala CompACT akan diberikan pada peserta untuk mengukur sejauh mana kemampuan masing-masing aspek pelatihan acceptance and commitment. Skala ini terdiri atas 23 item yang akan mengukur 6 aspek pada acceptance and commitment therapy yang dimampatkan menjadi 3 faktor. Menurut Hayes et al (2011), psychological inflexibility dapat dibagi menjadi 3 proses yang berpasangan, yaitu (1) openness to experience and detachment from literality yang terdiri dari acceptance dan defusion; (2) self awareness and perspective taking yang terdiri dari present moment awareness dan self as context; (3) motivation and activation yang terdiri dari values dan committed to action. Ketiga hal inilah yang menjadi 3 faktor yang diukur dalam proses acceptance and commitment therapy dan menggunakan CompACT. Kedua skala ini akan diberikan baik diawal maupun diakhir penelitian. Pemberian alat ukur sebelum penelitan dilakukan dimaksudkan untuk mengukur baseline partisipan, sedangkan alat ukur yang diberikan setelah penelitian telah diberikan digunakan sebagai post-test. Setelah data terkumpul, peneliti mengolah hasil penelitian dengan menggunakan SPSS versi 22.

\section{HASIL}

Hasil dari pemberian kedua alat ukur adalah sebagai berikut:

\section{- DERS}

Tabel 2 Hasil Uji Normalitas Pre Test dan Post Test DERS

Uji Normalitas

\begin{tabular}{|c|c|}
\hline Asymp.Sig Pre Test & 0.200 \\
\hline Asymp.Sig PostTest & 0.091 \\
\hline
\end{tabular}

Berdasarkan hasil uji normalitas (tabel

2) yang telah dilakukan oleh peneliti, nilaisignifikansi yang muncul pada pretest sebesar 0.200 dan post test sebesar 0.091. Hasil tersebut menunjukkan bahwa nilai signifikasi baik pre test dan post test menunjukkan bahwa sebaran data tergolong normal ( $\mathrm{sig}>0.05)$. Dengandemikian, uji beda data selanjutnya akan menggunakan pengujian para metrik dengan menggunakan paired samplet-test. 
WIBISONO- Efektivitas Pelatihan Acceptace 291

- CompACT

Tabel 3 Hasil Uji Normalitas Pre Test dan Post Test CompACT

UjiNormalitas

\begin{tabular}{lc}
\hline Asymp.Sig Pre Test & 0.200 \\
\hline Asymp.Sig PostTest & 0.016 \\
\hline \multicolumn{2}{c}{ Berdasarkan hasil uji normalitas (tabel }
\end{tabular}

3) yang telah dilakukan oleh peneliti, nilai signifikansi yang muncul pada pretest sebesar 0.200 dan post test sebesar 0.016. Hasil tersebut menunjukkan bahwa nilai signifikasi baik pre test dan post test menunjukkan bahwa sebaran data tergolong normal (sig $>0.05$ ). Dengan demikian, uji beda data selanjutnya akan menggunakan pengujian parametrik dengan menggunakan paired samplet-test.

Setelah peneliti memperoleh data normalitas dari setiap alat ukur yang akan digunakan, pemeriksa melakukan uji beda pada pre test dan post test dari kedua alat ukur yang ada (tabel 4 dan 5).

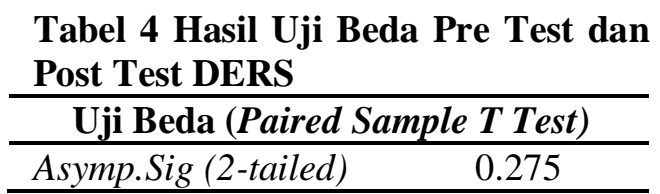

Tabel 5 Hasil Uji Beda Pre Test dan Post Test CompACT

\begin{tabular}{|c|c|}
\hline Uji Beda (Paired S & T Test) \\
\hline Asymp.Sig (2-tailed) & 0.002 \\
\hline
\end{tabular}
menunjukkan signifikasi (2-tailed) sebesar 0,275 (sig>0.05). Hal ini menunjukkan bahwa tidak ada perbedaan antara skor pre test dan post test pada variabel difficultiesin emotion regulation yang artinya tidak muncul perubahan setelah dilakukan intervensi. Berbeda dengan hasil dari tabel 4 , hasil yang telah diperoleh di tabel 5 menunjukkan signifikansi (2-tailed) sebesar 0,002 (sig>0.05). Hal ini menunjukkan bahwa ada perbedaan antara skor pretest dan posttest pada acceptance and commitment sehingga dapat disimpulkan bahwa adanya peningkatan pada penerimaan emosi negatif pendamping untuk mempermudah proses regulasi emosi negatif yang dirasakan, meningkatnya fleksibilitas psikologi pendamping agar dapat menerima berbagai perubahan karakteristik anak yang diasuh, dan terciptanya komitmen pengasuh untuk mengasuh anak-anak sesuai nilai-nilai kristiani yang ditanamkan didalam panti.

Selain mengukur perbedaan dengan menggunakan skala DERS dan CompACT, peneliti juga mengukur perbedaan pengetahuan yang didapatkan oleh paritisipan dalam pelatihan ini. Berikut data mengenai perbedaan rata-rata dan hasil uji beda pengetahuan peserta sebelum dan sesudah pelatihan:

Tabel 6 Nilai Mean Pre Test Dan Post Test Evaluasi Knowledge

\begin{tabular}{lc}
\hline & Mean \\
Pre Test & 5.80 \\
Post Test & 8.73 \\
\hline
\end{tabular}

Tabel 7 Hasil Uji Beda Skor PreTest dan Post Test Evaluasi Knowledge

\begin{tabular}{ll}
\hline \multicolumn{2}{c}{ Uji Beda (Wilcoxon) } \\
\hline Asymp. Sig (2-tailed) & 0.001 \\
\hline Berdasarkan data pada tabel & 6 , tampak
\end{tabular}

bahwa terdapat kenaikan nilai rata-rata pada aspek pengetahuan sebelum dan sesudah pelatihan berlangsung. Untuk dapat mengetahui signifikasi perubahan knowledge yang terjadi, maka akan dilakukan uji non parametrik dengan 
menggunakan Wilcoxon. Melalui tabel 7di atas, emosi dalam pelatihan acceptance and diketahui bahwa terdapat perbedaan yang commitment yang dilakukan sekitar delapan signifikan pada evaluasi knowledge sebelum hingga 10 sesi selama delapan sampai 10 dan sesudah pelatihan, yaitu sebesar 0.001 minggu (Khakbaz et al., 2016 \&Norouzi et al., $($ sig<0.05). Berdasarkan data ini, dapat 2017). Faktor selain waktu yang dapat diketahui bahwa pelatihan yang diberikan menyebabkan penelitian ini kurang berhasil efektif dalam memberikan pengetahuan baru adalah perbedaan individu, seperti bagi para peserta yang mengikutinya.

\section{PEMBAHASAN}

Secara keseluruhan, pelatihan acceptance and commitment training yang diadakan oleh peneliti belum menunjukkan perbedaan yang signifikan pada kemampuan dalam meregulasi emosi secara kuantitatif. Hasil ini berbeda dengan penelitian sebelumnya yang menyebutkan bahwa acceptance and commitment therapy efektif dalam menurunkan kesulitan dalam meregulasi emosi (Norouzi et al., 2017). Serupa dengan penelitian terdahulu yang telah disebutkan, penelitian dari Khakbaz et al.,(2016)juga menyatakan bahwa acceptance and commitment therapy yang dilakukan secara berkelompok dapat secara efektif meningkatkan kemampuan seseorang dalam meregulasi emosinya, yang artinya akan menurunkan kesulitan dalam meregulasi emosi yang dimiliki.

Perbedaan hasil penelitian ini, salah satunya dapat dijelaskan oleh pendapat dari Gross dan Jazaieri (2014) bahwa regulasi emosi merupakan proses yang memerlukan waktu untukdapat diterapkan pada diri seseorang. Berdasarkan penelitian terdahulu, proses individu untuk mempelajari regulasi kepribadian, jenis kelamin, dan usia (Wang\&Saudino, 2013; Gross 2014). Menurut penelitian tersebut, individu dengan jenis kelamin laki-laki menunjukkan kemampuan regulasi emosi yang lebih rendah dari pada perempuan (Wang\&Saudino, 2013; Gross 2014). Usia partisipan penelitian ini juga relatif pada tahapan emerging adulthood (Arnett,2000) sehingga diperhadapkan pada banyak kondisi yang memicu stres sosio emosionalnya yang dapat menggagalkan regulasi emosi yang dilakukannya (Gross, 2014).

Meskipun belum menunjukkan hasil yang signifikan pada perubahan kemampuan peserta untuk meregulasi emosinya, Hal ini dapat dilihat pada perubahan skor pada level learning knowledge yang menyatakan bahwa terdapat perbedaan yang signifikan antara sebelum pelatihan dan sesudah pelatihan dengan nilai signifikansi sebesar 0.01. Artinya pelatihan ini memberi pengetahuan baru bagi peserta mengenai materi yang diberikan selama pelatihan berlangsung. Hal ini didukung pula dengan perbedaan nilai mean sebelum dan sesudah pelatihan yang meningkat sebesar 2.93 poin.

\section{SIMPULAN}


Pelatihan acceptance and commitment

therapy yang dilakukan untuk menurunkan kesulitan regulasi emosi (DERS) pada pendamping panti asuhan $\mathrm{K}$ dapat disimpulkan kurang berhasil. Hal ini tampak berdasarkan hasil telaah lebih lanjut sebagai berikut:

1. Karakteristik anak yang diasuh, dan terciptanya komitmen pengasuh untuk mengasuh anak-anak sesuai nilai-nilai kristiani yang ditanamkan didalam panti.

2. Walaupun tidak berefek secara langsung pada penurunan kesulitan meregulasi emosi, pelatihan ini berhasil memberikan kontribusi pengetahuan pada para pendamping panti asuhan $\mathrm{K}$ yang menjadi partisipan penelitian ini.

Kelemahan dari penelitian adalah beberapa peserta datang terlambat sehingga acara pelatihan dimulai tidak sesuai dengan rundown dan beberapa peserta kurang fokus mengikuti pelatihan karena harus menjalankan kewajibannya seperti mengurus anak-anak yang sudah pulang sekolah sehingga harus meninggalkan ruangan pelatihan selama beberapa saat. Selain itu, pada penelitian ini tidak diukur intensitas emosi yang dirasakan oleh partisipan. Menurut Gross, (2014), kemampuan dalam meregulasi emosi juga dipengaruhi oleh intensitasemosi yang dirasakan. Jika intensitas emosi yang dirasakan semakin tinggi, maka semakin banyak usaha yang harus dilakukan untuk meregulasi emosi dan sebaliknya. Hal ini yang dapat menggagalkan pemilihan teknik regulasi emosi yang perlu dilakukan oleh partisipan (Gross 2013 \& Sheppes et al., 2014).

\section{Daftar Rujukan}

Arnett, J. J. (2000). Emerging adulthood: A Theory of Development From Late Teens Through The Twenties. American Psychological Association, 55(5). 469-480.

Carr, A. (2001). Family theraphy: Concepts, process, and practice. New York: John Willey \& Sons, Inc.

Cluver, L. D. \& Gardner, F., \& Operario, D. (2008). Effects of Stigma on the Mental Health of Adolescents Orphaned by AIDS. Journal of Adolescent Health. 42 (4), 410 $-417$.

Dingle, G. A., \& Fey, C., (2016). Tuned In: The Effectiveness for Young Adults of a Group Emotion Regulation Program Using Music Listening. Psychology of Music, 1-17.

Garner, P. W., \& Spears, F M. (2000). Emotion regulation in low-income preschool children. Social Development, 9, 246-264.

Gross, J. J., \& Munoz, R. F. (1995). Emotion regulation and mental health. Clinical Psychology: Science and Practice. 2, 151164.

Gross, J. J. (2013). Emotion regulation: taking stock and moving forward. American Psychologucal Association. 13(3). 359-365.

Gross, J. J. (2014). Handbook of Emotion Regulation $\left(2^{\text {nd }} E d\right.$.). New York: The Guilford Press.

Gross, J. J. \& Jazaieri, H. (2014). Emotion, emotion regulation, and psychopatology: an effective science perspective.Clinical Psychological Science. 2(4). 387-401.

Hayes, S. C., Villatte, M., Levin, M., \& Hildebrandt, M. (2011). Open, aware, and active:Contextual approaches as an emerging trend in the behavioral and cognitivetherapies. Annual Review of Clinical Psychology, 7(4), 141-168. 
Khakbaz, H., Farhoudian, A., Azkhosh, M., Journal of Behavioral Development, 38(2),

Dolatshahi, B., Karami, H., Massah,

O.(2016). The Effectiveness of Group

Acceptance and Commitment Therapy on

Emotion Regulation in Methamphetamine-

Dependent Individuals Undergoing

Rehabilitation. International Journal of

High Risk Behavior, 5(4).

Lawson, K. (2015). The trainer's handbook.

New York:John Willey \& Sons, Inc.

Norouzi, M., Zargar, F., \&Norouzi F.(2017).

Effectiveness of Acceptance and

Commitment Therapy on Interpersonal

Problems and Difficulties in Emotion

Regulation Among University Students.

Iran Journal Psychiatry Behavior Science.

Rif'ati, M. I. \& Suryanto, S. (2018). Pola

Regulasi Emosi Orang Tua dengan Anak

Temper Tantrum. Makalah disampaikan

pada Temu Ilmiah Nasional Ikatan

Psikologi Sosial, Universitas Katolik

Widya Mandala, Surabaya.

Solari, C. D., \& Mare, R. D. (2012). Housing crowding effects on children's wellbeing. Social science research, 41(2), 464-476.

Surjastuti, C. S. I. (2012). Landasan Konseptual Perencanaan dan Perancangan Panti Asuhan Anak Terlantar di Yogyakarta. (Skripsi). Yogyakarta: Universitas Katolik Atma Jaya.

Wang, M. \& Saudino, K. J. (2011). Emotion Regulation and Stress. Journal of Adult Development, 18(2). 95-103.

Yendork, S. J. \& Somhlaba, N. Z. (2014).

Stress, Coping and Quality of Life: An Exploratory Study of the Psychological Well-being of Ghanaian Orphans Placed in Orphanages. Children and Youth Services Riview, 1(46), 28 - 37.

Zimmermann, P. \& Iwanski, A. (2014).

Emotion Regulation from Early

Adolescence to Emerging Adulthood and Middle Adulthood: Age Differences, Gender Differences, and Emotion-Specific Develommental Variations. Internation 